\section{Cureus}

\title{
Solid Variant of an Aneurysmal Bone Cyst of the Thoracic Spine
}

\author{
Varshil Mehta ${ }^{1}$, Pravin Padalkar ${ }^{2}$, Maya Kale ${ }^{3}$, Ambadas Kathare ${ }^{2}$ \\ 1. Department of Internal Medicine, Seven Hills Hospital, Mumbai 2. Department of Orthopedics and \\ Spine, Center for Orthopaedic \& Spine Surgery, New Panvel, India 3. Department of Microbiology, MGM \\ Medical College, Navi Mumbai, India
}

$\square$ Corresponding author: Varshil Mehta, varshil91@gmail.com

Disclosures can be found in Additional Information at the end of the article

\section{Abstract}

The solid variant of an aneurysmal bone cyst $(\mathrm{ABC})$ has been observed very rarely, especially those involving the spine. In this case report, we present a very unusual tumour of the thoracic spine which was managed by $360^{\circ}$ decompression via posterior-only approach and stabilization.

A 16-year-old boy presented to us with a sudden onset of weakness in both lower limbs leading to paraplegia. He also had a history of back and chest pain over the past one year. A collapse of the $\mathrm{T} 5$ vertebrae on plain radiograph was observed. The patient was immediately shifted to the operation theatre with an initial plan of a total en bloc spondylectomy of the T5. However, intraoperatively, histology favored a solid-ABC variant rather than a spindle cell tumour or giant cell tumour. Thus, the initial plan was revised to a $360^{\circ}$ decompression without resecting the body en bloc via a posterolateral approach.

After surgery, complete resolution of his sensory and motor dysfunction was achieved. His chest and back pain also resolved. The diseased vertebral body gradually healed and new bone formation was seen at 18 months postoperatively.

This case report concludes that a solid variant of an ABC should be considered as a differential diagnosis for tumours involving the spine. An intraoperative frozen section procedure should be undertaken, especially during emergency situations. Early diagnosis and appropriate surgical management play an important role in the successful management of a solid variant of ABC.

Categories: Internal Medicine, Pathology, Orthopedics

Keywords: abc, osteolytic lesion, bone tumor

\section{Introduction}

The solid variant of an aneurysmal bone cyst $(\mathrm{ABC})$ is a very rare case which generally accounts for about $3.4 \%$ to $7.5 \%$ of all $\mathrm{ABCs}$ [1]. It is a cystic lesion that can occur and expand in any part of the bone, often affecting individuals in the second decade of their lives [2]. A definitive diagnosis is impossible but there are radiographic characteristics that are highly suggestive of ABCs on computed tomography (CT) and magnetic resonance imaging (MRI) scans.

Jaffe and Lichtenstein first described ABC in 1942, when they noted, "a peculiar bloodcontaining cyst of large size" [3]. As many as 69\% of primary ABCs demonstrate a characteristic clonal $\mathrm{t}(16 ; 17)$ genetic translocation which can lead to an upregulation of the TRE17/USP6 oncogene [4]. 


\section{Cureus}

Although benign, an $\mathrm{ABC}$ has the potential to grow acutely. Its expansile nature can cause a lot of swelling and pain while disrupting the growth plates. The changes in the bone can also lead to deformity and pathological fractures. It can also cause some neurological manifestations depending upon its location [2]. A distinct solid variant of ABC was first reported by Sanerkin, et al. in 1983 [5]. This type of solid variant could be easily misdiagnosed as a spindle cell tumour, especially osteosarcoma [1].

Symptomatic ABCs are generally treated with surgery. However, asymptomatic ABCs (characterized by clinically insignificant destruction of the bone) are generally left alone with just close monitoring for any abnormal changes [6].

\section{Case Presentation}

A 16-year-old boy was presented to us with a sudden onset of weakness in both lower limbs leading to paraplegia. He also had a history of back and chest pain over the last one year. A good rectal tone without any perineal anesthesia was noted in the rectal examination and the post-void residual urine volume was negligible. All laboratory findings were within normal range. Plain x-ray showed the collapse of the T5 vertebra (Figure 1).

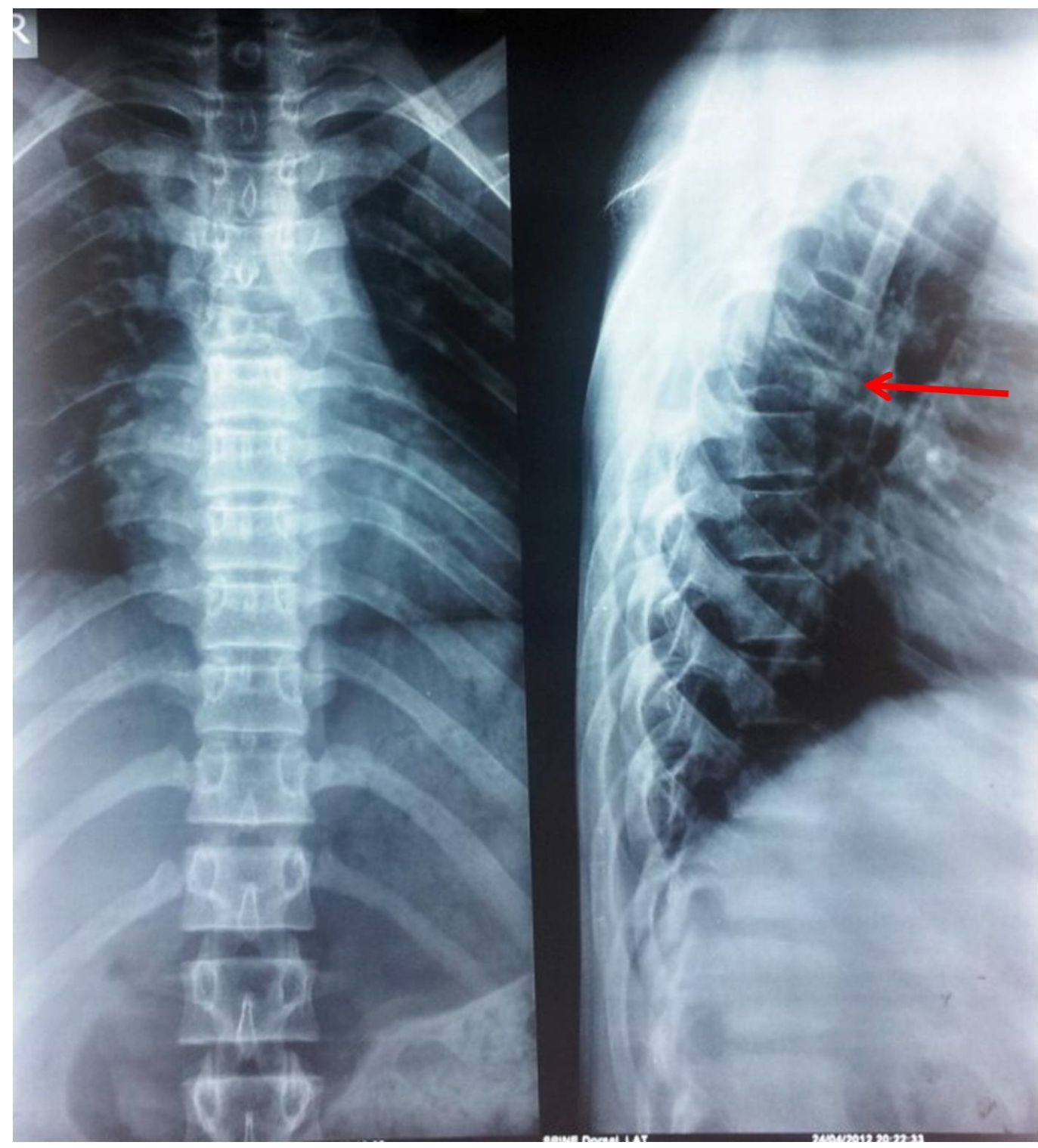

FIGURE 1: Radiograph showing collapse of T5 vertebra 


\section{Cureus}

Anteroposterior and lateral view $\mathrm{x}$-ray of the thoracic spine showing pathological fracture and collapse of $\mathrm{T} 5$.

CT axial images showed an expansile and lytic lesion in the vertebral body, left pedicle, and transverse process. T2-weighted sagittal and axial MRI T2-weighted images of the thoracic spine showed hyperintense signals in the $\mathrm{T} 5$ vertebral body, left pedicle, and transverse process with a pathological fracture (Figure 2).
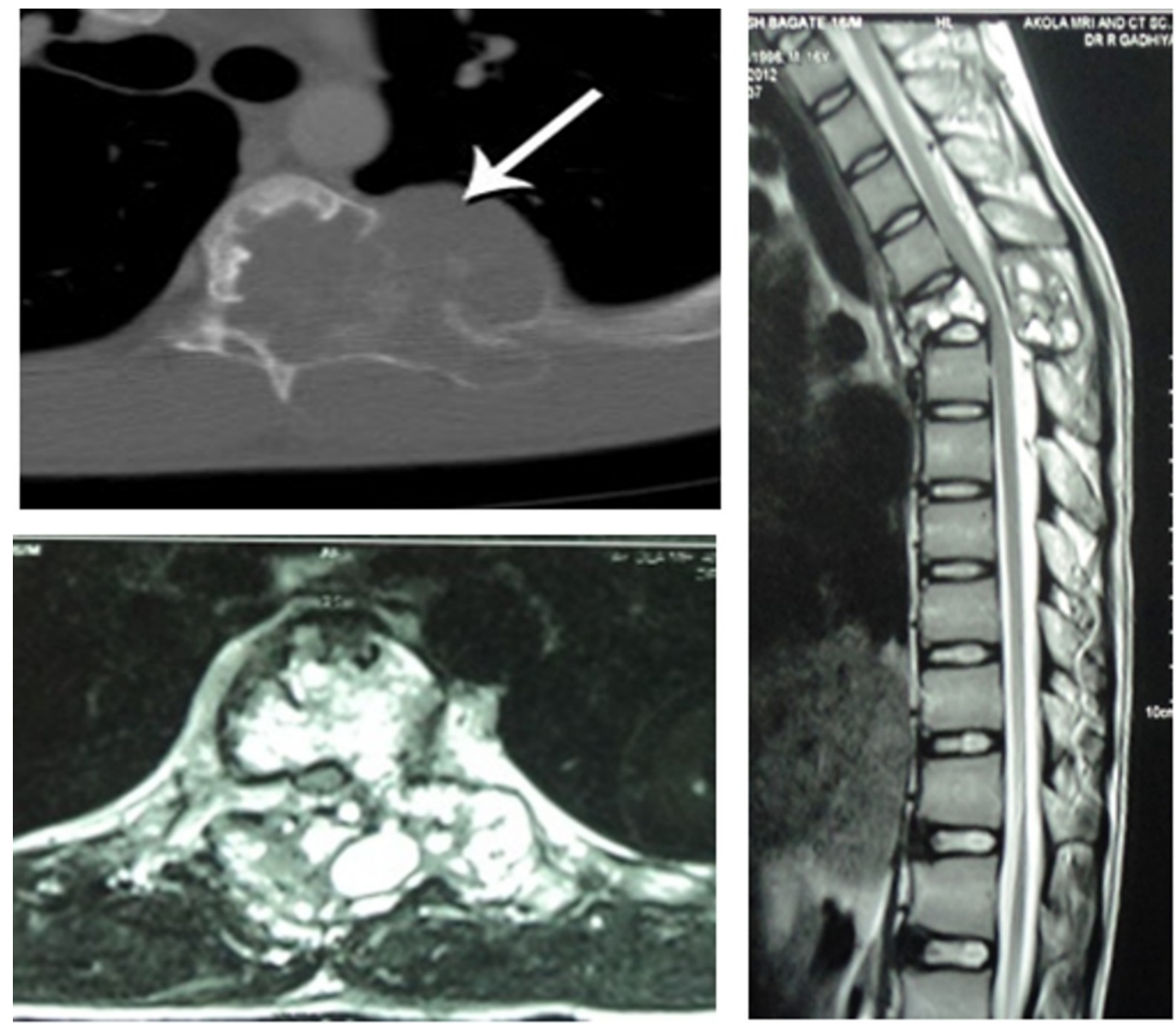

FIGURE 2: CT (top left) and MRI (bottom left and right)

Computed tomography (CT), magnetic resonance imaging (MRI).

A preoperative biopsy was not successful because of the urgent requirement of decompression. The patient was taken to the operating room on an emergency basis with an initial plan of a total en bloc spondylectomy of the T5.

Intraoperatively, histology favored a solid-ABC variant rather than a giant cell tumour. Thus, the initial plan was revised to palliative surgery with a $360^{\circ}$ decompression (without resecting the body) en bloc via a posterolateral approach as shown in Figure 3. The vertebral column was reconstructed with an expandable titanium cage (inserted via a costotransversectomy approach) and pedicle screw fixation in a $360^{\circ}$ manner (Figure 3). 


\section{Cureus}
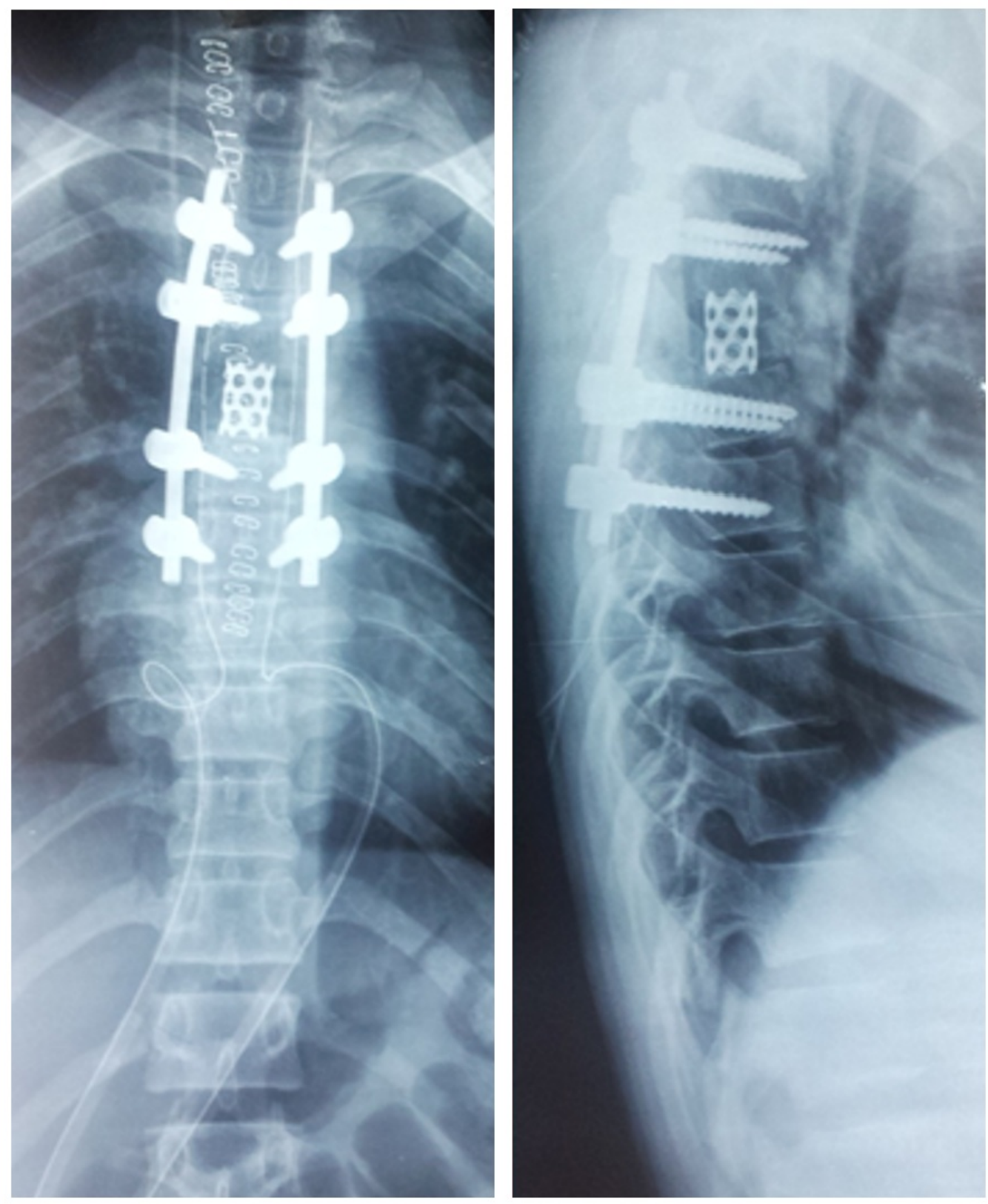

FIGURE 3: Intraoperative anteroposterior and lateral view x-ray of the thoracic spine showing cage and pedicle screw fixation

\section{Results}

After surgery, a complete resolution of sensory and motor functions was achieved. The pain in his chest and back also resolved gradually within a few days. Also, the diseased vertebral body gradually healed and new bone formation was seen at 18 months postoperatively (Figure 4). 


\section{Cureus}
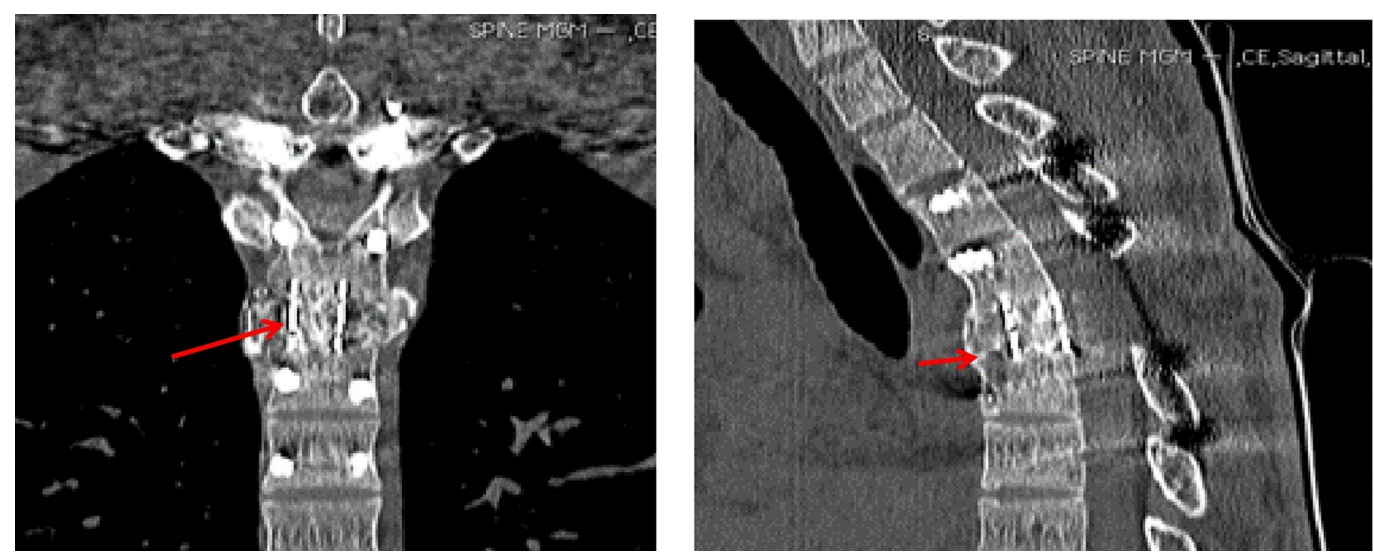

FIGURE 4: Postoperative MRI showing new bone formation at 18 months

Magnetic resonance imaging (MRI)

\section{Discussion}

ABCs, although benign, are locally very aggressive and highly vascularised tumours. Generally, post-surgery, it takes a long time to obtain a healing state and new bone formation with a recurrence rate of about 50\% [7]. However, Malghem, et al. concluded that spontaneous healing is possible [8].

$\mathrm{ABCs}$ are found to have a predilection for the lumbar spine, which was reported by Boriani, et al. [9]. Although CT and MRI scans are the preferred diagnostic methods, a biopsy is the utmost necessary prerequisite for confirming the diagnosis, due to its similarity in appearance with many other bone lesions. The biopsy generally shows proliferating round or oval cells, generally mixed with multinucleated giant cells distributed randomly. It also contains regions of reactive fibroblastic proliferation and microcystic components filled with blood [10].

Depending on the proliferative component, the solid variant of an $\mathrm{ABC}$ is often misdiagnosed histologically for other benign or malignant tumour-like bone lesions [1]. The pathological differential diagnosis (solitary bone cyst, giant cell tumour, hemangioma, osteosarcoma, and chondroblastoma) should always be kept in mind while thinking of ABC [10].

The treatment of $\mathrm{ABC}$ is also very controversial which includes arterial embolization, curettage with or without bone grafting, complete excision, intralesional drug injections (steroid and calcitonin), and radiation. However, early diagnosis and appropriate surgery play the most important role in the successful management of ABC [10].

Whether surgical management results in a better outcome and lower recurrence rate than other methods (conservative or palliative; for example, curettage alone) remains controversial. Hence, more studies comparing these methods should be conducted.

\section{Conclusions}

This case report concludes that an $\mathrm{ABC}$ should be kept as a differential diagnosis for tumours involving the spine. Intraoperative frozen sections should always be performed when there is a doubt in mind and in cases of emergencies. An effective spinal decompression and stabilization of the $\mathrm{ABC}$ can be achieved by partial or subtotal excision. However, for the successful 
management of $\mathrm{ABC}$, early diagnosis and appropriate surgical management should be considered.

\section{Additional Information \\ Disclosures}

Human subjects: Consent was obtained by all participants in this study. Conflicts of interest: In compliance with the ICMJE uniform disclosure form, all authors declare the following:

Payment/services info: All authors have declared that no financial support was received from any organization for the submitted work. Financial relationships: All authors have declared that they have no financial relationships at present or within the previous three years with any organizations that might have an interest in the submitted work. Other relationships: All authors have declared that there are no other relationships or activities that could appear to have influenced the submitted work.

\section{References}

1. Bertoni F, Bacchini P, Capanna R, Ruggieri P, Biagini R, Ferruzzi A, Bettelli G, Picci P, Campanacci M: Solid variant of aneurysmal bone cyst . Cancer. 1993, 71:729-34. 10.1002/1097-0142(19930201)71:3<729::AID-CNCR2820710313>3.0.CO;2-0

2. Clayer M: Injectable form of calcium sulphate as treatment of aneurysmal bone cysts . ANZ J Surg. 2008, 78:366-70. 10.1111/j.1445-2197.2008.04479.x

3. Jaffe HL, Lichtenstein L: Solitary unicameral bone cyst: with emphasis on the roentgen picture, the pathologic appearance and the pathogenesis. Arch Surg. 1942, 44:1004-25. 10.1001/archsurg.1942.01210240043003

4. Panoutsakopoulos G, Pandis N, Kyriazoglou I, Gustafson P, Mertens F, Mandahl N: Recurrent $\mathrm{t}(16 ; 17)(\mathrm{q} 22 ; \mathrm{p} 13)$ in aneurysmal bone cysts. Genes Chromosomes Cancer. 1999, 26:265-66. 10.1002/(SICI)1098-2264(199911)26:3<265::AID-GCC12>3.0.CO;2-\%23

5. Sanerkin NG, Mott MG, Roylance J: An unusual intraosseous lesion with fibroblastic, osteoclastic, osteoblastic, aneurysmal and fibromyxoid elements. "Solid" variant of aneurysmal bone cyst. Cancer. 1983, 51:2278-86. 10.1002/10970142(19830615)51:12<2278::AID-CNCR2820511219>3.0.CO;2-Y

6. Aneurysmal Bone Cyst. (2015). Accessed: 14th April, 2017: http://emedicine.medscape.com/article/1254784-overview\#a11.

7. Ruiter DJ, van Rijssel TG, van der Velde EA: Aneurysmal bone cysts. A clinicopathological study of 105 cases. Cancer. 1977, 39:2231-39. 10.1002/1097-0142(197705)39:5<2231::AIDCNCR2820390541>3.0.CO;2-Q

8. Malghem J, Maldague B, Esselinckx W, Noel H, De Nayer P, Vincent A: Spontaneous healing of aneurysmal bone cysts. A report of three cases. J Bone Joint Surg Br. 1989, 71:645-50.

9. Boriani S, De Iure F, Campanacci L, Gasbarrini A, Bandiera S, Biagini R, Bertoni F, Picci P: Aneurysmal bone cyst of the mobile spine: report on 41 cases . Spine (Phila Pa 1976). 2001, 26:27-35. 10.1097/00007632-200101010-00007

10. Saccomanni B: Aneurysmal bone cyst of spine: a review of literature . Arch Orthop Trauma Surg. 2008, 128:1145-47. 10.1007/s00402-007-0477-6 